\title{
IMPACT OF SEEDLING INFECTION OF SEPTORIA TRITICI BLOTCH ON BREAD WHEAT
}

\author{
M. Aydogdu \\ Department of Plant Health, Batı Akdeniz Agricultural Research Institute, Antalya, Turkey \\ Corresponding author's e-mail: mehmet9498@yahoo.com
}

\begin{abstract}
Septoria tritici blotch (STB), caused by the fungus Zymoseptoria tritici (Roberge ex Desm.) Quaedvl. \& Crous, poses a serious threat to bread wheat (Triticum aestivum L.) production around the world. Although there are various studies related to STB, impact of seedling infection on growth of bread wheat have not been well documented yet. The aims of the study were to examine host-pathogen interactions at the seedling stage and then monitor impact of seedling infection on plant growth. A total of 20 bread wheat cultivars were used as host plants and tested in the greenhouse. Seedlings of the cultivars at the two and three-leaf stages were inoculated with $Z$. tritici. Responses of the cultivars were determined using 0 to 5 scale. Fully-grown plants were evaluated for impact of STB on some agronomic traits (grain weight and plant height) of wheat. The cultivars showed different responses to Z. tritici. However, cvs. Adana-99, Ziyabey-98, Karatopak, Yakamoz and Ceyhan-99 were moderately resistant while cvs. Yüreğir-89 and Pamukova-97 were highly susceptible. STB infection at the seedling stage caused significant $(\mathrm{p} \leq 0.01)$ reduction in plant height ranging from 3.5 to $10.8 \%$ and grain losses 11.2 to $34.2 \%$ among the cultivars. The study suggests that when $Z$. tritici infects bread wheat at the seedling stage, it can significantly affect plant growth and grain yield of the crop.
\end{abstract}

Key words: Grain loss, interaction, plant height, Triticum aestivum, Zymoseptoria tritici. https://doi.org/10.36899/JAPS.2021.2.0239

Published online October 03,2020

\section{INTRODUCTION}

Bread wheat (Triticum aestivum L.) is a major crop and staple food for human in the world. Septoria tritici blotch (STB), caused by Zymoseptoria tritici (sexual stage: Mycosphaerella graminicola), is one of the main constraint to wheat production. It is prevalent in almost all wheat growing areas. Disease incidence in bread wheat may range from 52 to $75 \%$ (Tadesse et al., 2018), while it could be on average $60 \%$ in durum wheat (Chedli et al., 2018). Yield losses from STB might reach up to $40 \%$ (Tiley et al., 2018). In Europe, cost of fungicides used in the management of STB is nearly $€ 1$ billion per year (Kettles and Kanyuka, 2016). Despite huge economic importance of STB, publications regarding grain losses based on solid facts are hard to find (Fones and Gurr, 2015). In addition, little is known about how STB infection at the seedling stage can affect plant growth and accordingly grain formation of wheat. In this regard, Zhang et al. (2002) reported that screening STB at seedling stage ensures consistent data about host response, and repeated evaluation might not be necessary to get reliable information of host reaction. In addition, there is a high positive correlation between seedling and adult plant STB scores, therefore, screening STB can be conducted on seedling plants (Somasco et al., 1996). However, studying STB-resistance necessitates a method that can score the phenotype and be applicable to large populations, thus, testing genotypes at the seedling growth stage could be suitable (McCartney et al., 2002; Mergoum et al., 2007; Brown et al., 2015).

In Argentina, most commercially grown cultivars were classified from moderately resistant to susceptible (Simon et al., 2005). However, of the thirtyfour winter wheat genotypes originated from the Great Plains of the United States of America, eight were considered as resistant to STB, two were moderately resistant, and nine were moderately susceptible (Zhang et al., 2002). Resistance to STB varies depending on wheat genotypes, isolate of STB and environmental conditions. On the other hand, the most complicating factors in determining resistance to STB are the interactions among resistance, plant height, heading date and so on (Simon et al., 2005). Related to these, opposite findings exist in literature (Paraschivu et al., 2013; Miedaner et al., 2013). In addition, little is known regarding infections of STB at early growth stages of wheat. In this context, it is important that infections of the disease should be monitored from onset of the disease on wheat to initiate early management practices. The novelties of the present study were to examine seedling infection of STB on wheat under high disease pressure and then monitor impact of STB on wheat until harvest of the crop. In the study, correlations between STB severity and plant growth and grain weight were evaluated based on perceptible data and discussed with existing other findings. 
Thus, the aims of the present study were to examine host-pathogen interaction at the seedling stage on the basis of host responses and to determine overall impact of seedling infection of STB on some agronomic traits (plant height and grain yield) of bread wheat.

\section{MATERIALS AND METHODS}

Plant material: A total of 20 bread wheat cultivars (Yakamoz, Metin, Beşköprü, Pamukova-97, Adana-99, Altın Başak, Osmaniyem, Yüreğir-89, Gökhan, Cumhuriyet-75, Basribey-95, Gönen-98, Kaşifbey, Koç2015, Pandas, Karatopak, Ceyhan-99, BATEM-1, Hanlı and Ziyabey-98) were used as host plants in the experiments. Seeds of these cultivars were taken from Variety Registration and Seed Certification Center in Ankara, Turkey.

Isolation, identification and propagation of $Z$. tritici: A single pycnidium of $Z$. tritici isolated from diseased wheat leaf was used for inoculation. Infected leaf containing pycnidia of $Z$. tritici were collected from bread wheat producing fields of Aksu District of Antalya Province in 2018. Using a sterile needle, a small amount of pycnidium on the leaf was removed and mounted on slide and examined with an Olympus BX43 microscope. Based on morphological characteristics, such as hyaline, threadlike rods, usually curved conidia (Figure 1) with three to five inconspicuous septa ranging from 47 to 88 $\mu \mathrm{m} \times 1.8$ to $2.67 \mu \mathrm{m}, Z$. tritici was microscopically confirmed (Zillinsky, 1983; Ponomarenko et al., 2011).

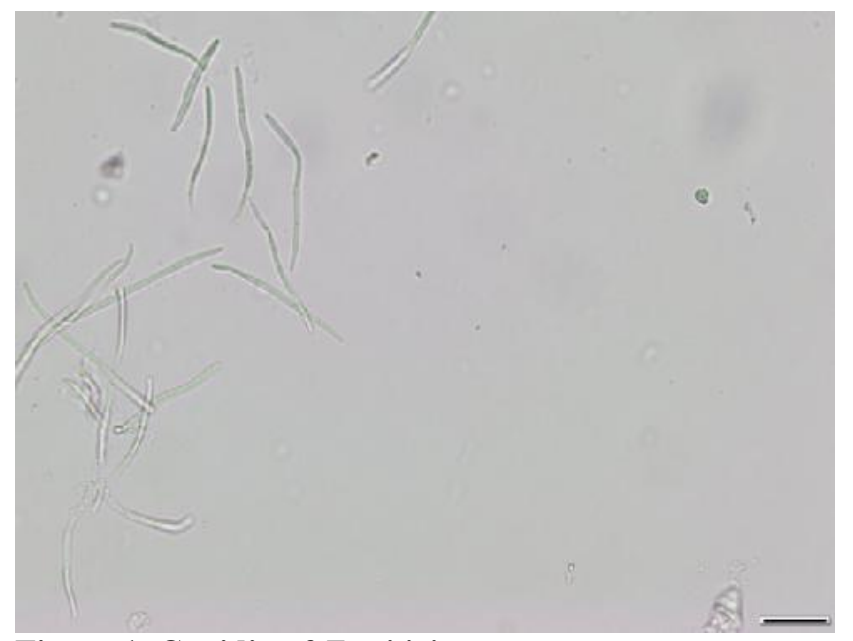

Figure 1. Conidia of $Z$. tritici.

Afterwards, the leaf segment $4-5 \mathrm{~cm}$ long containig pycnidia was placed on glass microscope slide on filter paper saturated with sterile water in a petri dish. It was incubated at $24{ }^{\circ} \mathrm{C}$ for $72 \mathrm{~h}$. The petri dish was observed every two hours for cirrhi emergence. Following emergence of cirrhi on pycnidia, a single cirrhus was taken from one pycnidium of the leaf segment through a sterile fine-pointed needle and transferred to yeast malt agar ( $4 \mathrm{~g}$ of yeast extract, $4 \mathrm{~g}$ of malt extract, $4 \mathrm{~g}$ of sucrose, and $15 \mathrm{~g}$ of agar in $1 \mathrm{~L}$ of water) plate containing streptomycin $(50 \mathrm{mg} / \mathrm{L})$. Later, it was streaked across the agar surface to separate individual pycniospores. The inoculated petri plates were kept at $20^{\circ} \mathrm{C}$ for one week. Ensuing this period, colonies developing from single pycnidiospores were transferred to yeast malt agar (YMA) without antibiotics. Eventually, one single spore was isolated from the pycnidium (Eyal et al.,, 1987; McKendry et al., 1995; Hayes et al., 2016). The pure isolate of $Z$. tritici was subcultured and propagated (Figure 2).

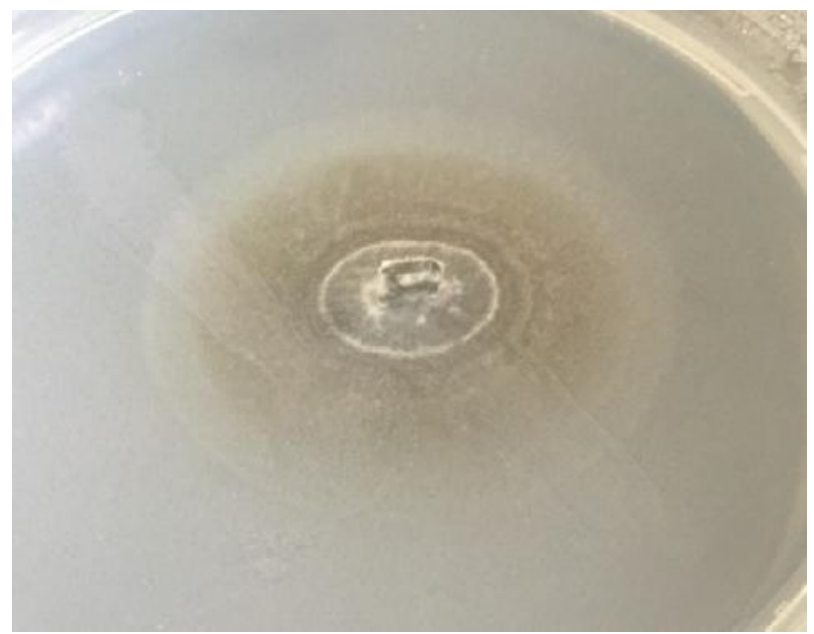

Figure 2. Colony development of $Z$. tritici on YMA.

Pathogenicity test: Ten seeds of cv. Kaşifbey were sown in $20 \mathrm{~cm}$-diameter pots containing autoclaved soil and vermiculite $(1: 1)$ in a greenhouse. $Z$. tritici growing on YMA was maintained for 10 days. Afterwards, $20 \mathrm{~mL}$ of sterile distilled water was added to each plate and pycnidiospores were filtered through four layers of cheeseclothe. The spore suspension was counted with a hemacytometer and adjusted to $2 \times 10^{7}$ spores $/ \mathrm{mL}$. Using this suspension, cv. Kaşifbey was inoculated through a hand sprayer at the two- to three-leaf stage. The pots were covered by transparent plastic bags and kept at $20^{\circ} \mathrm{C}$ with an $80 \%$ relative humidity for $48 \mathrm{~h}$ in a dark chamber and moved to greenhouse and kept at $25^{\circ} \mathrm{C}$ for 14 days (Mergoum et al., 2007).

After two weeks, typical symptoms of STB were observed and $Z$. tritici was reisolated from the artificially inoculated leaves and Koch's postulates were fulfilled.

Inoculum preparation: Apart from YMA, the isolate was propogated in Erlenmeyer flasks containing $50 \mathrm{ml}$ of yeast-malt-sucrose liquid media ( $4 \mathrm{~g}$ of yeast extract, $4 \mathrm{~g}$ of malt extract, $4 \mathrm{~g}$ of sucrose, and $1 \mathrm{~L}$ of $\mathrm{H}_{2} \mathrm{O}$ ) as follows: one mycelial plug $(0.5-\mathrm{cm}$ diameter $)$ of the isolate was transferred from YMA to the flask containing 
yeast-malt-sucrose liquid media. Later, flasks were sealed with sterile cotton plugs and placed on a shaker at $20{ }^{\circ} \mathrm{C}$ in the dark. After 7 days, the spore suspension was counted and adjusted to $2 \times 10^{7}$ spores $/ \mathrm{mL}$ using a hemacytometer (Mergoum et al., 2007; Stewart and McDonald, 2014).

Greenhouse experiment: The experiment was conducted in a completely randomized design with three replications and repeated two times, 14 seeds of each cultivars were sown in a pot $(20 \times 30 \mathrm{~cm})$ containing autoclaved soil and vermiculite $(1: 1)$ in a greenhouse. Three pots were considered as one experimental unit and, thus, a treatment consisted of 12 pots including controls. A total of 240 pots were assessed in the experiment. Seedlings at the two- to three-leaf stage (GS 12-13) (Zadoks et al., 1974) were inoculated with a $2 \times 10^{7}$ conidia suspension of $Z$. tritici using a hand sprayer and controls were sprayed with distilled water. To supply favorable conditions for STB, after inoculation, the pots were covered by transparent plastic bags and kept at $20^{\circ} \mathrm{C}$ with an $80 \%$ relative humidity for $48 \mathrm{~h}$ in a dark chamber and moved to greenhouse. The temperature of the greenhouse was maintained at 20 to $25^{\circ} \mathrm{C}$ and $85 \%$ relative humidity (Mergoum et al., 2007; Bastam et al., 2010).

Disease assesments: Seedlings were rated for STB infection 20 days after inoculation. Disease ratings were done using modified 0 to 5 scale, where $0=$ immune without visible symptoms; $1=$ highly resistant with small flecks; $2=$ resistant with small chlorotic or necrotic lesions; 3 = intermediate, characterized by coalescence of necrotic or chlorotic lesions normally toward the leaf tip and, to a lesser extent, elsewhere on the leaf blade; 4= susceptible, with coalesced necrotic lesions; and 5= highly susceptible, with large necrotic lesions extensively coalesced. Ratings of 0 to 2 were considered as resistant and 3 to 5 were considered as susceptible (McCartney et al., 2002; Mergoum et al., 2007).

In the present study, reaction types were categorized specifically as follows: $0=$ immune or highly resistant; 1= resistant; 2= moderately resistant; 3= moderately susceptible; $4=$ susceptible; and $5=$ highly susceptible. After disease assessment of the hosts, seedlings were maintained in the greenhouse for over 4 months. Ensuing this period, fully-grown plants were measured for plant height and then harvested by hand and grain weights of each cultivar were established.

Statistical analysis: Statistical procedures of SAS 9.1 software (SAS Institute Inc., Cary, NC, USA) were used for data analyses. Analyses of variance (ANOVA) were done using PROC ANOVA to determine whether treatments, varieties, and their interaction effects were statistically significant or not. Following ANOVA, treatments, varieties, and their interaction means were compared with SAS MEANS statements with Fisher's Protected LSD test option. Correlation analyses were conducted to determine relationships between plant characteristics and disease scores using SAS PROC CORR. On the other hand, figures were produced by Microsoft Office Excel software (Microsoft Office 2016) with a linear regression model.

\section{RESULTS}

Nearly two weeks after inoculation, typical symptoms of STB were observed on the leaves of the inoculated seedlings. The symptoms appeared as brown leaf spots, ash colored lesions expanding across leaf resulting in complete necrosis and tiny dark specks (pycnidia) (Figure 3).

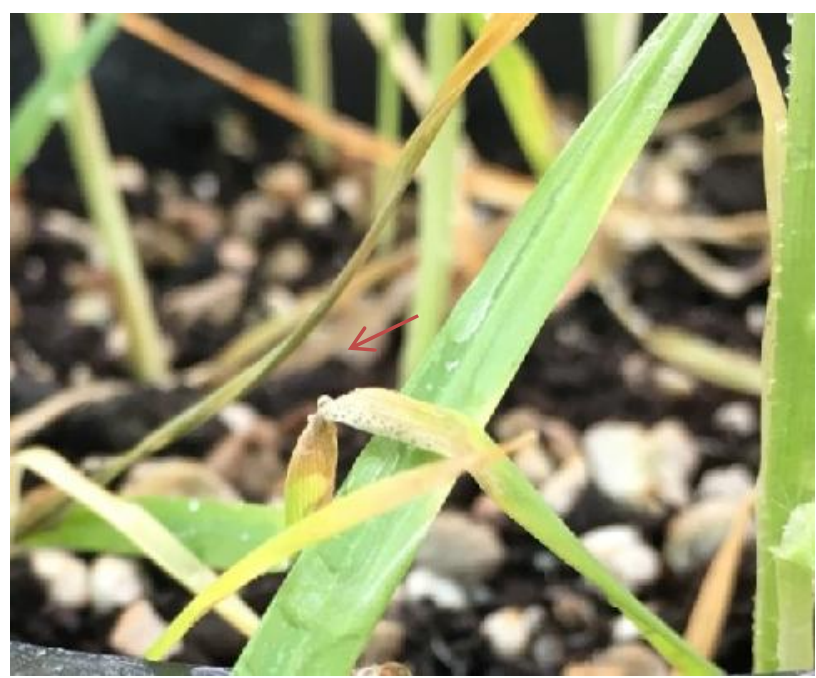

Figure 3. Necrosis and dark specks (pycnidia) (shown with red arrow) on the leaf of cv. Pandas.

Some cultivars for example cv. Gönen-98 was severely affected by the STB infection. Thus, almost all the leaves inoculated showed complete necrosis and abundant pycnidia on them. All plants were observed daily, effects of STB infection continued, as plants progressed.

To rate responses of the bread wheat cultivars, 0 to 5 scale was used (McCartney et al., 2002; Mergoum et al., 2007). No cultivar was resistant to Z. tritici but cvs. Adana-99, Ziyabey-98, Karatopak, Yakamoz and Ceyhan-99 were moderately resistant with the STB scores ranging from 2.0 to 2.6. However, cvs. Pamukova97 and Yüreğir-89 were highly susceptible to STB with 5.0 STB scores. As a result of artificial inoculation of bread wheat cultivars with $Z$. tritici, different host responses occurred ranging from moderately resistant to highly susceptible. However, the majority of the cultivars showed susceptible and highly susceptible response to STB (Table 1). 
Table 1. STB scores and responses of the cultivars and their grain weight comparison in inoculated and control plots.

\begin{tabular}{|c|c|c|c|c|c|c|}
\hline Cultivar & $\begin{array}{c}\text { Mean of } \\
\text { STB score }\end{array}$ & $\begin{array}{c}\text { STB } \\
\text { response }\end{array}$ & $\begin{array}{c}\text { Control } \\
(10 \text { spikes } / g) \\
\end{array}$ & $\begin{array}{c}\text { Inoculated (10 } \\
\text { spikes/g) }\end{array}$ & Mean & $\begin{array}{c}\text { Grainweight } \\
\text { loss (\%) }\end{array}$ \\
\hline Yakamoz & $2.6 \mathrm{~d}-\mathrm{f}$ & MR & $2.99 \mathrm{f}-\mathrm{h}$ & $2.481-0$ & $2.74 \mathrm{fg}$ & 17.0 \\
\hline Metin & $3.6 \mathrm{bc}$ & MS & $3.33 \mathrm{de}$ & $2.42 \mathrm{~m}-\mathrm{p}$ & $2.88 \mathrm{ef}$ & 27.3 \\
\hline Beşköprü & $4.6 \mathrm{a}$ & $\mathrm{S}$ & $3.47 \mathrm{~cd}$ & $2.35 n-q$ & $2.91 \mathrm{e}$ & 32.2 \\
\hline Pamukova-97 & $5.0 \mathrm{a}$ & HS & $3.91 \mathrm{~b}$ & $2.57 \mathrm{k}-\mathrm{n}$ & $3.24 \mathrm{c}$ & 34.2 \\
\hline Adana-99 & $2.3 \mathrm{ef}$ & MR & $2.701-1$ & $2.29 \mathrm{o}-\mathrm{s}$ & $2.50 \mathrm{~h} 1$ & 15.1 \\
\hline Altın Başak & $3.3 \mathrm{~cd}$ & MS & $3.64 \mathrm{c}$ & $2.86 \mathrm{~h}-\mathrm{j}$ & $3.25 \mathrm{c}$ & 21.4 \\
\hline Osmaniyem & $3.0 \mathrm{c}-\mathrm{e}$ & MS & $3.26 \mathrm{de}$ & $2.65 \mathrm{j}-\mathrm{m}$ & $2.96 \mathrm{de}$ & 18.7 \\
\hline Yüreğir-89 & $5.0 \mathrm{a}$ & HS & $2.43 \mathrm{~m}-\mathrm{p}$ & $1.63 \mathrm{v}$ & 2.031 & 32.9 \\
\hline Gökhan & $4.6 \mathrm{a}$ & $\mathrm{S}$ & $2.68 \mathrm{j}-1$ & $1.85 \mathrm{uv}$ & $2.26 \mathrm{jk}$ & 30.9 \\
\hline Cumhuriyet-75 & $4.6 \mathrm{a}$ & $\mathrm{S}$ & $2.99 \mathrm{f}-\mathrm{h}$ & $2.11 \mathrm{r}-\mathrm{t}$ & $2.55 \mathrm{~h}_{1}$ & 29.4 \\
\hline Basribey-95 & $3.6 \mathrm{bc}$ & MS & $3.97 \mathrm{~b}$ & $2.92 \mathrm{~g}-1$ & $3.44 \mathrm{~b}$ & 26.4 \\
\hline Gönen-98 & $4.3 \mathrm{ab}$ & $\mathrm{S}$ & $4.36 \mathrm{a}$ & $3.13 \mathrm{e}-\mathrm{g}$ & $3.74 \mathrm{a}$ & 28.2 \\
\hline Kaşifbey & $3.6 \mathrm{bc}$ & MS & $3.15 \mathrm{e}-\mathrm{g}$ & 2.31 o-r & $2.73 \mathrm{fg}$ & 26.6 \\
\hline Koç-2015 & $4.3 \mathrm{ab}$ & $\mathrm{S}$ & $4.44 \mathrm{a}$ & $3.17 \mathrm{ef}$ & $3.80 \mathrm{a}$ & 28.6 \\
\hline Pandas & $4.3 \mathrm{ab}$ & $\mathrm{S}$ & $2.84 \mathrm{~h}-\mathrm{j}$ & $2.01 \mathrm{tu}$ & $2.42 \mathrm{ij}$ & 29.2 \\
\hline Karatopak & $2.3 \mathrm{ef}$ & MR & $2.80 \mathrm{~h}-\mathrm{k}$ & $2.43 \mathrm{~m}-\mathrm{p}$ & $2.61 \mathrm{gh}$ & 13.2 \\
\hline Ceyhan-99 & $2.6 \mathrm{~d}-\mathrm{f}$ & MR & $3.34 \mathrm{de}$ & $2.83 \mathrm{~h}-\mathrm{j}$ & $3.09 \mathrm{~cd}$ & 15.2 \\
\hline BATEM-1 & $3.3 \mathrm{~cd}$ & MS & $2.14 \mathrm{q}-\mathrm{t}$ & $1.65 \mathrm{v}$ & 1.891 & 22.8 \\
\hline Hanlı & $3.0 \mathrm{c}-\mathrm{e}$ & MS & $2.22 \mathrm{p}-\mathrm{t}$ & $1.75 \mathrm{v}$ & 1.981 & 21.1 \\
\hline Ziyabey-98 & $2.0 \mathrm{f}$ & MR & 2.33 o-r & $2.07 \mathrm{~s}-\mathrm{u}$ & $2.20 \mathrm{k}$ & 11.2 \\
\hline Mean & 3.5 & MS & $3.15 \mathrm{a}$ & $2.37 \mathrm{~b}$ & $2.76 \mathrm{fg}$ & 24.0 \\
\hline
\end{tabular}

Cultivar LSD $(0.01)=0.218$ Treatment LSD $(0.01)=0.068$

Cultivar $\times$ treatment $\operatorname{LSD}(0.01)=0.308$

STB score $\operatorname{LSD}(0.01)=1.09$

Levels not connected by same letter are significantly different

After STB ratings of the cultivars, seedlings were maintained in the greenhouse for over 4 months. Ensuing this period, fully-grown plants were measured for plant height and then harvested by hand and grain weights were detected.
Compared with non-inoculated plants (controls), effect of the STB inoculation on plant height and grain yield of wheat cultivars were significant $(\mathrm{p} \leq 0.01)$. In addition, differences of responses of the cultivars were significant (Table 2).

Table 2. Variance analysis of plant height, yield and STB score.

\begin{tabular}{lcccccc}
\hline Source & DF & Plant height & Yield & Source & DF & STB \\
\hline Cultivar & 19 & $201.875^{* *}$ & $1.854^{* *}$ & Cultivar & 19 & $2.733^{* *}$ \\
Treatment & 1 & $585.208^{* *}$ & $17.956^{* *}$ & Error & 40 & 0.250 \\
Treatment $\times$ Cultivar & 19 & $2.489^{* *}$ & $0.149^{* *}$ & Total & 59 & \\
Error & 80 & 0.475 & 0.021 & & & \\
Total & 119 & & & & & 13.76 \\
CV $(\%)$ & 1.22 & 5.30 & & &
\end{tabular}

Mean grain weight (yield) of all the cultivars in control plots was $3.15 \mathrm{~g}$ while it was $2.37 \mathrm{~g}$ in inoculated ones, accordingly, STB infection at the seedling growth stage (GS 12-13) caused averagely $24.0 \%$ yield loss among the cultivars (Table 1). Depending on the cultivar, yield losses ranged from 11.2 (cv. Ziyabey-98) to $34.2 \%$ (cv. Pamukova-97) (Table 1). Mojerlou et al. (2009) stated that at three growth stages including tillering (GS
37), stem elongation (GS 45) and flag leaf opening (GS 53 ), yield reductions from STB might vary from 30 to $50 \%$, which supported the findings of the current study. Because, in the current study, symptoms of STB at the seedling growth stage (GS 12-13) continued distinctively until GS 45, indicating that influence of early seedling infection of STB may continue as plants progress. 
In the present study, a significant positive correlation $(\mathrm{r}=0.978, \mathrm{p} \leq 0.01)$ between grain weight loss and STB score was found, which means that the higher STB scores led to the greater grain losses (Table 3).

Table 3. Relationship between grain weight of spikes and STB score.

\begin{tabular}{lllll}
\hline & $\begin{array}{l}\text { Grain weight } \\
\text { control }\end{array}$ & $\begin{array}{l}\text { Grain weight } \\
\text { inoculated }\end{array}$ & STB score & Grain loss (\%) \\
\hline Grain weight (control) & $\begin{array}{l}1.000 \\
0.907^{* *}\end{array}$ & 1.000 & & \\
Grain weight (inoculated) & 0.350 & -0.060 & 1.000 & 1.000 \\
Mean of STB score & 0.351 & -0.070 & $0.978^{* *}$ & \\
Grain loss (\%) & & & &
\end{tabular}

**: Significant at $\mathrm{p} \leq 0.01$

The similar aspect was stated by Shtienberg (1991) and Camacho-Casas et al. (1995) with other approachment that a negative correlation exist between STB severity and grain weight. That is, as disease severity of STB increase, grain weight decrease.
Likewise, in the present study, a linear relationship between grain weight reduction and STB score was found (Figure 4), indicating that the higher STB score caused the higher grain weight reduction in the cultivars.

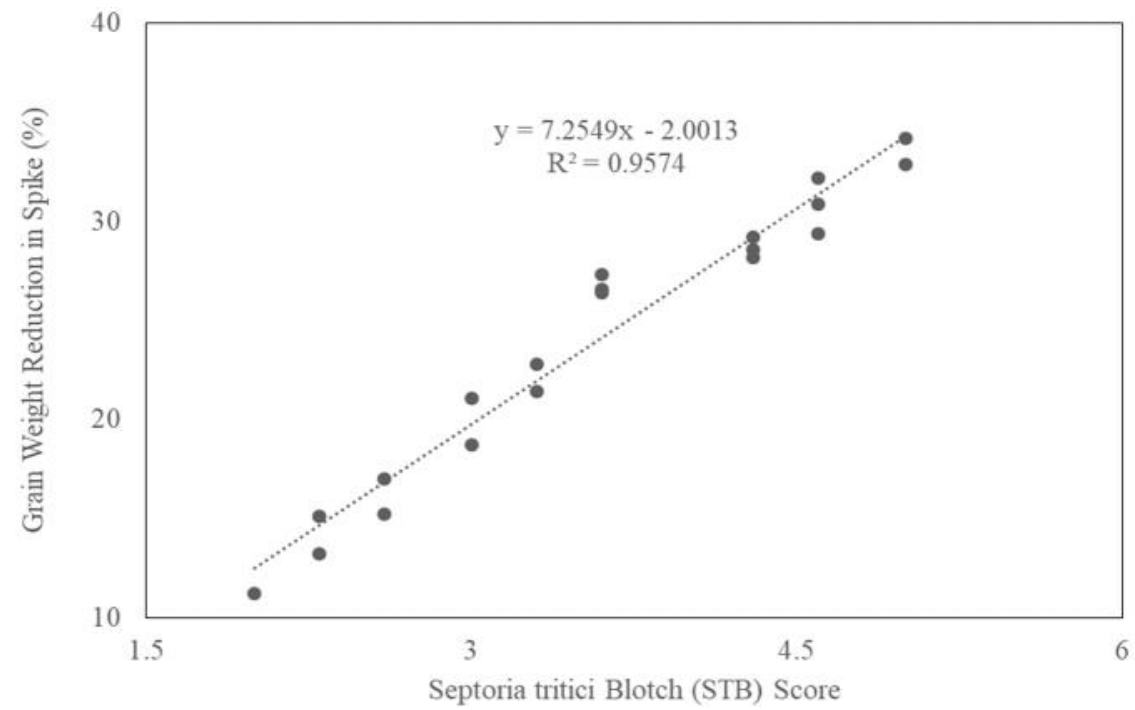

Figure 4. Association between STB score and grain weight reduction.

All inoculated plants were shorter than those of the non-inoculated and differences of height reduction in the cultivars were significant at $\mathrm{p} \leq 0.01$. Mean of plant height reduction (PHR) of all the cultivars was $7.5 \%$.
The highest PHR was found on cv. Beşköprü with a $10.8 \%$, while the least PHR was detected on cv. Ziyabey with a $3.5 \%$ (Table 4 ).

Table 4. Comparison of plant height of the cultivars in inoculated and control plots.

\begin{tabular}{lccccc}
\hline Cultivar & $\begin{array}{c}\text { Control } \\
(\mathbf{c m})\end{array}$ & $\begin{array}{c}\text { Inoculated } \\
(\mathbf{c m})\end{array}$ & Mean & $\begin{array}{c}\text { Mean of STB } \\
\text { score }\end{array}$ & $\begin{array}{c}\text { Height reduction } \\
(\%)\end{array}$ \\
\hline Yakamoz & $65.33 \mathrm{c}$ & $61.66 \mathrm{ef}$ & $63.50 \mathrm{c}$ & $2.6 \mathrm{~d}-\mathrm{f}$ & 5.6 \\
Metin & $60.66 \mathrm{f}-\mathrm{h}$ & $54.33 \mathrm{o}-\mathrm{q}$ & $57.50 \mathrm{f}$ & $3.6 \mathrm{bc}$ & 10.4 \\
Beşköprü & $67.66 \mathrm{~b}$ & $60.33 \mathrm{~g}-1$ & $64.00 \mathrm{c}$ & $4.6 \mathrm{a}$ & 10.8 \\
Pamukova-97 & $53.33 \mathrm{qr}$ & $47.66 \mathrm{vw}$ & $50.50 \mathrm{k}$ & $5.0 \mathrm{a}$ & 10.6 \\
Adana-99 & $62.66 \mathrm{e}$ & $59.33 \mathrm{r}-\mathrm{k}$ & $61.00 \mathrm{~d}$ & $2.3 \mathrm{ef}$ & 5.3 \\
Altın Başak & $55.33 \mathrm{~m}-\mathrm{o}$ & $50.66 \mathrm{t}$ & $53.00 \mathrm{~d}$ & $3.3 \mathrm{~cd}$ & 8.4 \\
Osmaniyem & $58.33 \mathrm{kl}$ & $53.33 \mathrm{qr}$ & $55.83 \mathrm{~g}$ & $3.0 \mathrm{c}-\mathrm{e}$ & 8.5 \\
Yüreğir-89 & $60.00 \mathrm{~h} 1$ & $54.00 \mathrm{pq}$ & $57.00 \mathrm{f}$ & $5.0 \mathrm{a}$ & 10.0
\end{tabular}




\begin{tabular}{|c|c|c|c|c|c|}
\hline Gökhan & $53.33 \mathrm{qr}$ & $49.33 \mathrm{u}$ & $51.33 \mathrm{j}$ & $4.6 \mathrm{a}$ & 7.5 \\
\hline Cumhuriyet-75 & $61.33 \mathrm{fg}$ & $56.33 \mathrm{~m}$ & $58.83 \mathrm{e}$ & $4.6 \mathrm{a}$ & 8.1 \\
\hline Basribey-95 & $54.00 \mathrm{pq}$ & $48.66 \mathrm{uv}$ & $51.33 \mathrm{j}$ & $3.6 \mathrm{bc}$ & 9.8 \\
\hline Gönen -98 & $52.66 \mathrm{rs}$ & $47.66 \mathrm{vw}$ & $50.16 \mathrm{k}$ & $4.3 \mathrm{ab}$ & 9.4 \\
\hline Kaşifbey & $47.33 \mathrm{w}$ & $44.33 \mathrm{x}$ & 45.831 & $3.6 \mathrm{bc}$ & 6.3 \\
\hline Koç-2015 & $56.00 \mathrm{~m}$ & $52.33 \mathrm{rs}$ & $54.16 \mathrm{~h}$ & $4.3 \mathrm{ab}$ & 6.5 \\
\hline Pandas & $52.00 \mathrm{~s}$ & $47.66 \mathrm{vw}$ & $49.83 \mathrm{k}$ & $4.3 \mathrm{ab}$ & 8.3 \\
\hline Karatopak & $69.33 \mathrm{a}$ & $66.00 \mathrm{c}$ & $67.66 \mathrm{a}$ & $2.3 \mathrm{ef}$ & 4.8 \\
\hline Ceyhan-99 & $58.66 \mathrm{j}-1$ & $55.33 \mathrm{~m}-\mathrm{o}$ & $57.00 \mathrm{f}$ & $2.6 \mathrm{~d}-\mathrm{f}$ & 5.6 \\
\hline BATEM-1 & $59.66 \mathrm{mn}$ & $55.66 \mathrm{~h}-\mathrm{j}$ & $57.66 \mathrm{f}$ & $3.3 \mathrm{~cd}$ & 6.7 \\
\hline Hanlı & 57.661 & $54.66 n-p$ & $56.16 \mathrm{~g}$ & $3.0 \mathrm{c}-\mathrm{e}$ & 5.2 \\
\hline Ziyabey-98 & $66.33 \mathrm{c}$ & $64.00 \mathrm{~d}$ & $65.16 \mathrm{~b}$ & $2.0 \mathrm{f}$ & 3.5 \\
\hline Mean & $58.58 \mathrm{a}$ & $54.16 \mathrm{~b}$ & 56.37 & 3.5 & 7.5 \\
\hline
\end{tabular}

Cultivar LSD $(0.01)=1.05$

Treatment LSD $(0.01)=0.33$

Cultivar $\times$ treatment $\operatorname{LSD}(0.01)=1.49$

Levels not connected by same letter are significantly different

A significant positive correlation $(\mathrm{r}=0.766$, $\mathrm{p} \leq 0.01$ ) was found between PHR and STB score. As STB score increased and accordingly PHR soared (Table 5). No genetic associations between earliness, plant height, and resistance to STB are evident (Simon et al., 2005).
However, a significant low negative correlation $(\mathrm{r}=$ $0.444, p \leq 0.05$ ) between plant height of the cultivars in controls (non-inoculated) with STB score was detected in the present study (Table 5).

Table 5. Relationship between plant height and STB score.

\begin{tabular}{lcccc}
\hline & Control & Inoculated & STB score & Plant height reduction \\
\hline Control & 1.000 & & & \\
Inoculated & $0.975^{* *}$ & 1.000 & & \\
Mean of STB Score & $-0.444^{*}$ & $-0.581^{* *}$ & 1.000 & \\
Plant height reduction (PHR) & -0.292 & $-0.493^{*}$ & $0.766^{* *}$ & 1.000 \\
\hline
\end{tabular}

${ }^{* *}$ : significant at $\mathrm{p} \leq 0.01,{ }^{*}:$ significant at $\mathrm{p} \leq 0.05$.

This finding supported previous several studies. In this regard, Camacho-Casas (1989) reported a negative correlation value of $\mathrm{r}=-0.53$ between plant height and STB severity. Risser et al. (2011) also found a significant $(\mathrm{p} \leq 0.01)$ but low negative correlation between STB severity and plant height $(\mathrm{r}=-0.20)$. The same aspect was emphasized by Paraschivu et al. (2013) with the negative correlation between plant height and STB progress $(\mathrm{r}=-0.72)$. In addition, a linear positive association between reduction in plant height and STB score was detected in the present study (Figure 5).

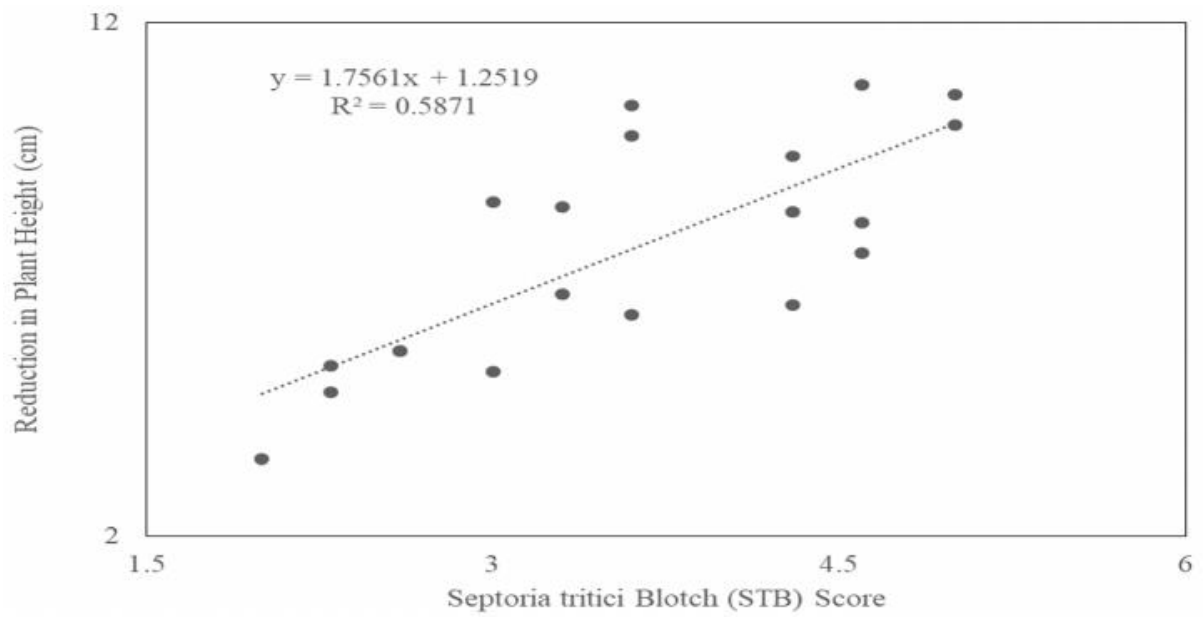

Figure 5. STB score and reduction in plant height. 


\section{DISCUSSION}

Infection of STB occurs as extracellular colonisation of leaves in wheat (Rudd et al., 2015). STB reduces photosynthetic activity in infected leaves by reducing green leaf area because of the lesions themselves and also, possibly, by stimulating senescence in infected leaves of wheat. Thus, induced-apical senescence could be an important damage of STB (Zuckerman et al., 1997; Robert et al., 2006). However, little is known about how STB infection at the seedling growth stage can affect the whole plant. In the present study, aforementioned typical symptoms of STB were observed on the leaves at the seedling stage. Moreover, STB infection at the seedling stage caused significant decrease in plant height in inoculated plots. This could be explain as follows: high disease pressure occurred with the presence of ample conidia of STB, favorable conditions and susceptible hosts. Thus, STB infection appearing at early growth stage of wheat may have caused stress on the young plants. To respond to this stress induced by STB, plants may have shifted their normal metabolic activities by curtailing their normal fully growth period for survival, inducing stunting of the plants. In this regard, Robert et al. (2004) emphasized that main effect of STB is a reduction in green leaf area, which may lead to more than $70 \%$ of reduction in plant growth. Cornish et al. (1990) stated that infection of wheat by STB reduces water use and growth in wellwatered, well-managed crops. Several researchers (Kolomiets, 1999; Slimane et al., 2012) also reported that STB induces a decrease in assimilation surface, green area, developmental retardation, premature leaf desiccation, and 1000-grain weight and grain quality. As for Mihailova et al. (2019), they stated that STB had a negative influence on physiological and biochemical activity of winter wheat genotypes. Apart from these, in a study, related to Pyricularia oryzae, the causal agent of blast disease in rice, Koutroubas et al. (2009) reported that plants grown under high disease levels (inoculated) showed reduced plant height and grain yield. In the present study, wheat plants, adversely affected by STB infection and accordingly physiological activities, may not have displayed their normal plant growth and yield potential, thus, STB may have induced significant grain weight reduction in inoculated plants. Likewise, Lynch et al. (2016) emphasized that grain-filling capability of wheat decreases due to infection and necrosis on leaves caused by STB. In the present study, by comparing control plots, grain losses from STB was detected up to $34.2 \%$. This finding also presents a new perceptible data about impact of infection of STB on wheat at the seedling stage. In literature, absence of solid data regarding impact of STB infection at the seedling stage on grain weight of wheat makes it difficult to discuss the finding of the present study with grain weight losses data based on STB infection at other growth stages of wheat. However, to give an example, inoculating three spring-wheat cultivars at five different growth stages with STB resulted in significant differences in STB scores and grain yield and the highest foliage infections of STB were found at the early leafy stages of the cultivars (Williams and Gareth Jones, 1972).

In the management of STB, fungicides are generally used. However, fungicide resistance has been oftenly reported (Hayes et al., 2016; Kettles and Kanyuka, 2016; Kildea et al., 2019). Because, STB may overcome fungicides through its genetic variability. Thus, using resistant cultivars seems to be a plausible approach in the management of the disease. Moreover, breeding programs should be constantly maintained to improve new wheat cultivars resistant to STB (Ghaffary et al., 2018; Hassine et al., 2019). Screening existing wheat cultivars for resistance to STB is crucial for farmers and plant breeders as well. In the present study, host (registered Turkish bread wheat cultivars) responses varied from moderately resistant to highly susceptible depending on the bread wheat cultivars but majority of the cultivars generally displayed a susceptible response to STB, indicating vulnerability of the bread wheat cultivars. Likewise, Aydoğdu and Kurbetli (2018) found that bread wheat cultivars were moderately susceptible to STB under natural epidemic conditions of the Mediterranean region of Turkey. With regard to durum wheat, in a study conducted at seedling and adult plant gowth stages, it was found that durum wheat genotypes had various STB resistance sources (Ouaja et al., 2020). As for Brokenshire (1976), the author reported that bread wheat cultivars may show a wide range of STB reaction ranging from high resistance to high susceptibility. Similar reports about host responses of commercially grown cultivars and winter wheat genotypes in South and North America were given by some researchers (e.g. Zhang et al., 2002; Simon et al., 2005). As it is known that interactions among host, pathogen, and environment designate plant response. Thus, in the present study, under the same conditions, that is, using the same isolate of STB and providing the same environmental conditions in the greenhouse, host's response emerged depending on the each cultivar.

Conclusion: STB infection might occur at any phenological stage of wheat and causes important economic losses around the world. However, knowledge in particular regarding STB infection at seedling stage of wheat and its impact on plant growth are quite limited. Based on perceptible data, the present study showed that STB infection at seedling stage may adversely affect plant growth and accordingly grain formation in bread wheat. In addition, in the present study, for the first time, registered Turkish bread wheat cultivars were secreened for resistance to STB at the seedling stage. Further 
studies are needed to reveal economic aspects related to infections of STB at early growth stages of wheat.

\section{REFERENCES}

Aydoğdu, M. and İ. Kurbetli (2018). Determination of prevalence of foliar fungal diseases in wheat in the western mediterranean region of Turkey and host responses. Proc. VII. Turk. Plant Prot. Cong. 14-17 Nov. p. 66 (in Turkish)

Bastam, S.V., S.S. Ramezanpour, H. Soltanloo, S. Kia, M. Kalate, and M.H. Pahlevani (2010). Inheritance of resistance to septoria tritici blotch (STB) in some Iranian genotypes of wheat (Triticum aestivum L.). Int. J. Gen. Mol. Bio. 2(3): 34-42.

Brokenshire, T. (1976). The reaction of wheat genotypes to Septoria tritici. Ann. Appl. Bio. 82(3): 415423.

Brown, J.K.M., L. Chartrain, P. Lasserre-Zuber, and C. Saintenac (2015). Genetics of resistance to Zymoseptoria tritici and applications to wheat breeding. Fun. Genet. Bio. 79: 33-41.

Camacho-Casas, M.A. (1989). Inheritance of septoria leaf blotch resistance and the possible influence of heading date and plant height on the disease expression in a winter wheat cross. A thesis of doctor of philosophy submitted to Oregon State Univ. U.S.

Camacho-Casas, M.A., W.E. Kronstad, and A.L. Scharen (1995). Septoria tritici resistance and associations with agronomic traits in a wheat cross. Crop Sci. 35(4): 971-976.

Chedli, R.B.H., S.B. M'Barek, A. Yahyaoui, Z. Kehel, and S. Rezgui (2018). Occurrence of septoria tritici blotch (Zymoseptoria tritici) disease on durum wheat, triticale, and bread wheat in northern Tunisia. Chil. J. Agric. Res. 78(4): 559568.

Cornish, P.S., G.R. Baker, and G.M. Murray (1990). Physiological responses of wheat (Triticum aestivum) to infection with Mycosphaerella graminicola causing septoria tritici blotch. Austr. J. Agr. Res. 41(2): 317-327.

Eyal, Z., A.L. Scharen, J.M. Prescott, and M. van Ginkel (1987). The septoria diseases of wheat: concepts and methods of disease management. Mexico, D.F.: CIMMYT. $46 \mathrm{p}$

Fones, H. and S. Gurr (2015). The impact of septoria tritici blotch disease on wheat: An EU perspective. Fun. Genet. Bio. 79: 3-7.

Ghaffary, S.M.T., A. Chawade, and P.K. Singh (2018). Practical breeding strategies to improve resistance to septoria tritici blotch of wheat. Euphyt. 214: 122.
Hassine, M., A. Siah, P. Hellin, T. Cadalen, P. Halama, J.-L. Hilbert, W. Hamada, M. Baraket, A. Yahyaoui, A. Legreve, and M. Duvivier (2019). Sexual reproduction of Zymoseptoria tritici on durum wheat in Tunisia revealed by presence of airborne inoculum, fruiting bodies and high levels of genetic diversity. Fung. Bio. 123(10): 763-772.

Hayes, L.E., K.E. Sackett, N.P. Anderson, M.D. Flowers, and C.C. Mundt (2016). Evidence of selection for fungicide resistance in Zymoseptoria tritici populations on wheat in western Oregon. Plant Dis. 100: 483-489.

Kettles, G.J. and K. Kanyuka (2016). Dissecting the molecular interactions between wheat and the fungal pathogen Zymoseptoria tritici. Front. Plant Sci. 7: 508.

Kildea, S., D.E. Bucar, F. Hutton, S. de la Rosa, T.E. Welch, and S. Phelan (2019). Prevalence of QoI resistance and mtDNA diversity in the Irish Zymoseptoria tritici population. Irish J. Agr. F. Res. 58(1): 27-33.

Kolomiets, S. (1999). Populations of Septoria spp. affecting winter wheat in the forest-steppe zone of the Ukraine. Proc. Fif ${ }^{\text {th }}$ Int. Sept. Works. 2024 Sept. p. 32, CIMMYT, Mexico.

Koutroubas, S.D., D. Katsantonis, D.A. Ntanos, and E. Lupotto (2009). Blast disease influence on agronomic and quality traits of rice varieties under Mediterranean conditions. Turk. J. Agric. For. 33: 487-494.

Lynch, K.M., E. Zannini, J. Guo, C. Axel, E.K. Arendt, S. Kildea, and A. Coffey (2016). Control of Zymoseptoria tritici cause of septoria tritici blotch of wheat using antifungal lactobacillus strains. J. Appl. Mic. 121(2): 485-494.

McCartney, C.A., A.L. Brûlé-Babel, and L. Lamari (2002). Inheritance of race-specific resistance to Mycosphaerella graminicola in wheat. Phytopathol. 92: 138-144.

McKendry, A.L., G.E. Henke, and P.L. Finney (1995). Effects of septoria leaf blotch on soft red winter wheat milling and baking quality. Cereal Chem. 72(2): 142-146.

Mergoum, M., P.K. Singh, S. Ali, E.M. Elias, J.A. Anderson, K.D. Glover, and T.B. Adhikari (2007). Reaction of elite wheat genotypes from the northern great plains of North America to septoria diseases. Plant Dis. 91: 1310-1315.

Miedaner, T., Y. Zhao, M. Gowda, C.F.H. Longin, V. Korzun, E. Ebmeyer, E. Kazman, and J.C. Reif (2013). Genetic architecture of resistance to septoria tritici blotch in European wheat. BMC Genomic. 14: 858.

Mihailova, G., Z. Stoyanova, R. Rodeva, B. Bankina, G. Bimšteine, and K. Georgieva (2019). 
Physiological changes in winter wheat genotypes in response to the Zymoseptoria tritici infection. Photosynt. 57(2): 428-437.

Mojerlou, S., N. Safaie, A. Alizadeh, and F. Khelghatibana (2009). Measuring and modeling crop loss of wheat caused by septoria leaf blotch in seven cultivars and lines in Iran. J. Plant Protec. Res. 49(3): 257-262.

Ouaja, M., L. Aouini, B. Bahri, S. Ferjaoui, M. Medini, T.C. Marcel, and S. Hamza (2020). Identification of valuable sources of resistance to Zymoseptoria tritici in the Tunisian durum wheat landraces. Eur. J. Plant Pathol. 156: 647661.

Paraschivu, M., O. Cotuna, and M. Paraschivu (2013). The use of the area under the disease progress curve (audpc) to assess the epidemics of septoria tritici in winter wheat. Res. J. Agric. Sci. 45(1): 193-201.

Ponomarenko, A., S.B. Goodwin, and G.H.J. Kema (2011). Septoria tritici blotch (STB) of wheat. Plant Health Instructor. Doi:10.1094/PHI-I2011-0407-01

Risser, P., E. Ebmeyer, V. Korzun, L. Hartl, and T. Miedaner (2011). Quantitative trait loci for adult-plant resistance to Mycosphaerella graminicola in two winter wheat populations. Phytopathol. 101: 1209-1216.

Robert, C., M.-O. Bancal, P. Nicolas, C. Lannou, and B. Ney (2004). Analysis and modelling of effects of leaf rust and septoria tritici blotch on wheat growth. J. Expr. Bot. 55(399): 1079-1094.

Robert, C., M.-O. Bancal, C. Lannou, and B. Ney (2006). Quantification of the effects of septoria tritici blotch on wheat leaf gas exchange with respect to lesion age, leaf number, and leaf nitrogen status. J. Expr. Bot. 57(1): 225-234.

Rudd, J.J., K. Kanyuka, K. Hassani-Pak, M. Derbyshire, A. Andongabo, J. Devonshire, A. Lysenko, M. Saqi, N.M. Desai, S.J. Powers, J. Hooper, L. Ambroso, A. Bharti, A. Farmer, K.E. Hammond-Kosack, R.A. Dietrich, and M. Courbot (2015). Transcriptome and metabolite profiling of the infection cycle of Zymoseptoria tritici on wheat reveals a biphasic interaction with plant immunity involving differential pathogen chromosomal contributions and a variation on the hemibiotrophic lifestyle definition. Plant Physio. 167(3): 1158-1185.
Shtienberg, D. (1991). Effects of moisture and septoria tritici blotch stresses on wheat yields under semi-arid conditions: A Simulation study. Phytopar. 19: 301.

Simon, M.R., A.E. Perello, C.A. Cordo, S. Larran, P.E.L. van der Putten, and P.C. Struik (2005). Association between septoria tritici blotch, plant height, and heading date in wheat. Agron. J. 97: 1072-1081.

Slimane, R.B., P. Bancal, F. Suffert, and M.-O. Bancal (2012). Localized septoria leaf blotch lesions in winter wheat flag leaf do not accelerate apical senescence during The necrotrophic stage. J. Plant Pathol. 94(3): 543-553.

Somasco, O.A., C.O. Qualset, and D.G. Gilchrist (1996). Single-gene resistance to septoria tritici blotch in the spring wheat cultivar 'Tadinia'. Plant Breed. 115(4): 261-267.

Stewart, E.L. and B.A. McDonald (2014). Measuring quantitative virulence in the wheat pathogen Zymoseptoria tritici using high-throughput automated image analysis. Phytopath. 104: 985 992.

Tadesse, Y., A. Chala, and B. Kassa (2018). Survey of septoria tritici blotch (Septoria tritici) of bread wheat (Triticum aestivum L.) in the central highlands of Ethiopia. Amer. J. Biosc. Bioeng. 6(5): 36-41.

Tiley, A.M.M., G.D. Foster, and A.M. Bailey (2018). Exploring the genetic regulation of asexual sporulation in Zymoseptoria tritici. Front. Microbiol. 9: 1859.

Williams, J.R. and D. Gareth Jones (1972). Epidemiology of Septoria tritici and S. nodorum: VI. Effect of time of initial infection on disease development and grain yield in spring wheats. Transac. Brit. Mycol. Soc. 59(2): 273-283.

Zadoks, J.C., T.T. Chang, and C.F. Konzak (1974). A decimal code for the growth stages of cereals. Weed Res. 14: 415-421.

Zhang, X., S.D. Haley, and Y. Jin (2002). Repeatability of assays for seedling septoria tritici blotch resistance in winter wheat. Cereal Res. Com. 30(1/2): 157-163.

Zillinsky, F.J. (1983). Common diseases of small grains cereals: A guide to identification. Mexico, D.F. CIMMYT. $141 \mathrm{p}$

Zuckerman, E., A. Eshel, and Z. Eyal (1997). Physiological aspects related to tolerance of spring wheat cultivars to septoria tritici blotch. Phytopath. 87: 60-65. 